\title{
O ETHOS DO CUIDADO NA FORMAÇÃO DOCENTE: uma experiência de estágio no ensino superior
}

Clara Maria Miranda de Sousa*

Marcelo Silva de Souza Ribeiro**

\begin{abstract}
Resumo: Objetivou-se relatar a experiência de estágio docente no ensino superior em uma universidade pública, vivenciando o ethos do cuidado de maneira prática-reflexiva. Foi vivenciado por uma mestranda e o docente da disciplina (optativa) "Interfaces em Saúde e Educação", ofertado no curso de Psicologia. Fundamentou-se em Heidegger (2005), Boff (2013; 2014), Freire (2015) e Bondía (2017). Para tanto, relataram-se as 10 primeiras aulas, referente ao cuidar, indicando práticas de ethos do cuidado. A formação a partir do ethos do cuidado se mostrou como uma experiência exitosa, exercitando a docência com orientação, leveza, sensibilidade e atenção para com os caminhos percorridos.
\end{abstract}

Palavras-chave: Ethos do Cuidado. Formação. Estágio.

THE ETHOS OF CARE IN TEACHING TRAINING: an internship experience in higher education

\begin{abstract}
The objective was to report the experience of teaching internship in higher education in a public university, experiencing the ethos of care in a practical-reflective way. It was experienced by a master's student and the lecturer of the (optional) discipline "Interfaces in Health and Education", offered in the course of Psychology. It was based on Heidegger (2005), Boff (2013, 2014), Freire (2015) and Bondía (2017). With this aim, the first 10 classes related to care were reported on, indicating practices of care ethos. Training based on the ethos of care proved to be a successful experience, exercising teaching with orientation, lightness, sensitivity and attention to the covered paths.
\end{abstract}

Keywords: Ethos of Care. Formation. Internship.

\footnotetext{
* Pedagoga. Mestra em Educação pelo Programa de Pós-graduação em Formação de Professores e Práticas Interdisciplinares da Universidade de Pernambuco, Campus Petrolina (UPE). E-mail: claradassis@gmail.com

** Psicólogo. Doutor e Mestre em Ciências da Educação pela Université du Québec à Chicoutimi (UQAM). Professor da Universidade Federal do Vale do São Francisco (UNIVASF). E-mail: mribeiro27@gmail.com
} 


\section{Introdução}

A formação docente ao longo desses anos tem sido afirmada como campo fértil de pesquisa enquanto indicações para um fazer e ser profissional voltado às demandas que a realidade suscita. $\mathrm{O}$ professor, desde sua formação inicial, deve ter a consciência de que é um cuidador, já que suas ações implicam num envolvimento com o outro, pois a formação está imbricada em uma relação de cuidado. Assim, podemos refletir que a formação não se dá no treinamento em nível de capacitação via contatos mecânicos, mas vai muito além e perpassando por uma mudança de ser (BOFF, 2013; 2014).

Gois (2017) explana que a docência no ensino superior se apresenta assim, como em outros níveis de ensino, atravessada por atividades complexas e de ações humana. Seus desdobramentos provocam no profissional a exigência da busca por múltiplos saberes e a consequente formulação no seu processo identitário atualizado no cotidiano junto aos estudantes.

Através da Lei de no 9394 de 1996, temos as Diretrizes e Bases da Educação (LDB), em que, no art. 66, é apresentado que “a preparação para o exercício do magistério superior far-se-á em nível de pósgraduação, prioritariamente em programas de mestrado ou doutorado” (BRASIL, 1996). O caráter mais relacionado em como se dará a dimensão pedagógica no magistério superior não é sinalizado, assim o docente que não tenha experiência com a modalidade da educação superior deverá buscar por conta própria seu aprimoramento.

A partir destas colocações, este artigo tem como objetivo relatar a experiência de estágio docente no ensino superior em uma universidade pública, vivenciando o ethos do cuidado de maneira práticareflexiva. Este estágio docência foi possível por conta do componente obrigatório no Programa de PósGraduação em Formação de Professores e Práticas Interdisciplinares (PPGFPPI) da Universidade de Pernambuco (UPE) ${ }^{1}$ e desenvolvidos na época de sua realização, por uma mestranda em Educação e sob supervisão do seu orientador. A disciplina (optativa), Interfaces em Saúde e Educação, foi ofertada no curso de Psicologia numa outra universidade publica da região.

Em meio a experiência vivenciada ao longo da disciplina Interfaces Saúde e Educação se elege o ethos do cuidado como objeto de discussão. Toda a disciplina foi vivenciada a partir das ideias de que a formação é espaço de cuidado. Como afirma Souza, Caldas e De Antoni (2017), os estudantes estão envolvidos em uma estrutura que precisam o tempo todo estarem em atividade de estudo, avaliações e práticas que, muitas vezes, levam a se esquecerem de si mesmos. Além de que, em nosso país, temos uma cultura e um ambiente acadêmico em que se transita a competição, os conflitos e, consequentemente, o estresse (SOUZA; CALDAS; DE ANTONI, 2017).

\footnotetext{
${ }^{1}$ O Curso de Mestrado Profissional do Programa de Pós-Graduação em Formação de Professores e Práticas Interdisciplinares (PPGFPPI) da Universidade de Pernambuco (UPE), Campus Petrolina, busca formar profissionais conscientes da sua função social diante da complexidade educacional do semiárido nordestino.
} 
Relatar a experiência vivenciada corrobora com o pensamento de Bondía (2017) quando fala que a experiência passa de maneira aligeirada por falta de tempo e pelos excessos de informação e trabalho. Desse modo, a experiência vivenciada, tendo como centralidade o ethos do cuidado na disciplina de Interfaces Saúde e Educação, nos deu a possibilidade de parar para escutar os estudantes e suas angústias, nos demorar nos detalhes de planejamento, de imenso cultivo a atenção e ao encontro com o outro e para refletir alternativas de melhor estar no mundo.

Nosso artigo está organizado em quatro partes. Na primeira, trata-se da reflexão sobre a emergência do cuidado nas práticas formativas. A segunda, discute como fora vivenciado o estágio docência a partir do ethos do cuidado. A terceira parte, os resultados e discussões desta experiência são abordados, assim como a avaliação do processo vivenciado. Por fim, finalizamos o artigo com as considerações reflexivas quanto a prática em cuidado na formação do ensino superior.

\section{Ethos do cuidado: emergência na formação}

Antes de descrever como fora vivenciado o estágio docência no ensino superior envolvendo o ethos do cuidado, iremos comentar acerca do embasamento teórico que norteou a nossa prática ao longo das atividades vivenciadas com a turma da disciplina. Fomos, pois, envolvidos com a perspectiva fenomenológica, que tanto tem relação com a filosofia quanto com a psicologia, a partir das contribuições de Heidegger (2005) e de outros teóricos que balizaram a ideia de cuidado na formação em educação e saúde, como Boff (2013; 2014) e Freire (2015), além de explanar sobre a experiência a partir de Bondía (2017) para pensar e falar sobre o ethos do cuidado na formação docente.

Heidegger (2005) em sua obra intitulada "Ser e Tempo" enfatiza o cuidado como condição essencial para a existência de ser. Para tanto, utiliza do termo Sorge para denominar acerca de cuidado. Ao falar de cuidado Heidegger (2005) expõe que somos primordialmente ser junto com os outros e em processo de devir. Por sermos cuidado, a estrutura que nos envolve compreende existencialmente o ser presença de maneira indivisível, formando uma totalidade livre para novas possibilidades. Assim, o "ser sendo" cuidado é o que está agindo permanentemente no mundo, construindo projetos de devir com ética e sentido de existir.

Conforme Heidegger (2015), enquanto presença no mundo, temos a tarefa constante de analisar a nós mesmos, como nos comportamos e nos entregamos a realidade que nos é posta. Temos, pois, a responsabilidade de nos assumir enquanto ser dado e em construção. Para tanto, Heidegger (2005) utiliza do termo Dasein, enquanto ser-aí, que se mostra a partir do que se é, ou seja, só se compreende a partir de si mesmo, assim “deixar e fazer todos verem o ente em seu ser” (HEIDEGGER, 2015, p. 81).

O ser não é simplesmente um corpo humano, é, pois, um lançado no mundo. Não na dimensão de estar perdido em meio ao convívio junto a outros, mas o que se conecta a algo ou alguém, habitando o mundo na busca de sentido para sua existência. Nesse lançar-se, o ser se põe no empenho da relação, 
apreendendo saberes e modos-de-ser-no-mundo. Aos poucos o Dasein vai reconhecendo o mundo que habita e se responsabilizando por sua transformação.

No processo de transformação, o ser vivencia junto a outros as escolhas. Constantemente cada um está a escolher como pensar, expressar e agir diante das demandas que lhe são postas. O Dasein que toma consciência de sua existência está implicado a partir de sua postura ética. Ao explanar sobre ética, Boff (2014, p. 195) indica que "Ethos em grego significa [...] conjunto de princípios que regem, transculturalmente, o comportamento humano para que seja realmente humano no sentido de ser consciente, livre e responsável”.

Pensando na prática educativa, em conformidade com essa visão, Freire (2015) mostra que a ética não poderá estar separada da prática. Ao trabalharmos nos contextos educativos somos mediadores vivazes do ethos do cuidado pelas relações que estabelecemos uns com os outros. Assim, seria impossível dissociar a teoria da prática ao se tratar de cuidado, porque perpassa a ação no cotidiano.

O professor assumindo uma postura ética não consegue pensar em cuidado sem ver o próprio modo-de-ser. Ele é o exemplo mais próximo de ética, no fazer educativo junto a outros. Quem não lembra daquele professor(a) que o marcou de maneira positiva ou negativa, por conta do seu modo-deser? O modo-de-ser-cuidado revela de maneira concreta como é o ser humano. Desse modo, o ethos do cuidado nos ensina a nos desvelar e vivenciar a solicitude para com todos com a nossa ação (BOFF, 2014).

Enquanto formandos e formadores a prática que envolve cuidado deve permear dos laços afetivos, em que se dê a importância da escuta ao outro, da realidade e de si mesmo. Para Boff (2013), ao estar com o outro é importante que se viva a ternura, a compaixão e o cuidado. O professor que vivencia a sua prática pelo viés do cuidado, dá o devido espaço aos tempos de cada ser, permitindo que se revelem sem temor e sem julgar o outro, mas aceitando a todos e dialogando para que se (re)construam na convivência que o afeta sem o peso da culpa e da indiferença seja em si ou nas pessoas próximas.

O ethos do cuidado suscita que o equilíbrio possa acontecer, percebendo os limites de cada pessoa e alinhando para a justa medida em não inserir mais do que o outro não suporta (BOFF, 2014). $\mathrm{Na}$ formação mediada com cuidado, o tempo é essencial para que o conhecimento possa ser absorvido com tranquilidade e percebendo nuances que fazem com que o grupo seja gerado com harmonia e bem querer.

No ensino superior há a preocupação da voracidade de produção científica. Para Oliveira, Pereira e Lima (2017) a lógica do produtivismo na academia tem se crescimento na década de 1990, com o governo Fernando Henrique Cardoso, no qual implementou regras administrativas aos profissionais universitários para aumento da produção, direcionando o ensino, pesquisa e a formação para o mercado. Assim, exigências da Coordenação de Aperfeiçoamento de Pessoal de Nível Superior (CAPES) no campo universitário levou ao reforço de uma lógica individualista e produtivista, expressada pela enorme quantidade de artigos, que propiciam apenas quantidade e não qualidade no ensino e consequentemente formação. 
O professor cuidadoso, conseguirá (re)fazer e construir junto outros modos de produção, que não cause ansiedade nos alunos e muito menos adoecimento. Em nossa sociedade estamos envolvidos de muitos modos de expressão, assim o processo de aprendizagem envolvido de cuidado, indicará reflexões e modos práticos de reconstrução social pela atenção, zelo, preocupação e ocupação na tarefa contínua de ser-no-mundo (BOFF, 2014; HEIDEGGER, 2005).

Outra preocupação que podemos trazer quanto a justa medida do cuidado nos processos formativos, seria na dimensão de que o cuidado em seu excesso é destrutivo. O professor como mediador da aprendizagem compreende que há um tempo para tudo, mantendo a atenção na dosagem certa dos limites do grupo, assim como animar para maiores produções. Freire (2015) apresenta que o exercício da prática docente é um modo de cuidado. A formação é mais do que treinar o aluno, ela favorece o espaço para que mostre seus interesses e tenha condição de realizar escolhas pensando no bem-estar social.

Por seu turno, o termo "freireano" de Ser Mais, enquanto vocação ontológica, nos leva a pensar que somos capazes ontologicamente de cuidar, inicialmente de nós, aprendendo conjuntamente com o outro a ser presença no mundo e contribuir na transformação da sociedade. $\mathrm{Na}$ formação, todos se formam, tanto o que facilita o processo, quanto quem participa (FREIRE, 2015). O formando desde o princípio assume-se como sujeito que produz o seu saber. A democracia na prática da formação se coloca como elemento fundamental para se entender que todos são ensinantes e aprendentes (FREIRE, 2015).

Outra postura trazida por Freire (2015) e que se mostra importante na discussão de formação docente pautada no ethos do cuidado, seria a recusa pelo ensino bancário, um ensino que padroniza e molda o indivíduo a partir das ideologias dominantes. Para tanto, os saberes, carregados pelo contexto, merecem ser constantemente (re)visitados, sobretudo no aspecto de estar-junto e não como dominador. O papel de professor com cuidado é também exercer uma postura ética, crítica e política mediante aos atravessamentos da realidade que suscita pensar melhor, elaborar estratégias para os enfrentamentos sociais e refletir saídas que respeitem a todas as pessoas.

Enquanto docência, a convicção que deve reger é do inacabamento. Mesmo que proponha a mesma técnica, ainda assim temos que emanar que a prática é única e que não se repete, já que as pessoas e o momento são outros. A força criadora do aprender na formação do ethos de cuidado explora e produz junto com a curiosidade suscitada no convívio com os alunos. O momento, então, não é o de calar e se angustiar com as inquietudes da realidade, mas falar e construir um consenso de novos conhecimentos e práticas dialógicas (FREIRE, 2015).

Tudo o que tratamos até o momento quanto ao ethos do cuidado na prática da formação docente não é possível sem a experiência. É a experiência que solidifica conhecimento e que sensibiliza o ser para a mudança. Bondía (2017, p. 26) mostra que "é incapaz de experiência aquele a quem nada lhe passa, a quem nada lhe acontece, a quem nada lhe sucede, a quem nada o toca, nada lhe chega, nada o afeta, a quem nada o ameaça, a quem nada ocorre”. Lançamos, pois, a transposição para o fazer docente, em que 
o professor cuidadoso se envolve, se fere com a realidade, se reconstrói e que se afeta com cada pessoa que ali está responsável por mediar a aprendizagem.

É emergente que a formação docente seja um momento de experiência de cuidado. Bondía (2017) indica que o ser da experiência está aberto a deformação e transformação, um apaixonado pela possibilidade de criar, testemunhando publicamente a condição política e social das vigências reais. $\mathrm{O}$ professor envolvido de ethos do cuidado é um "escuta-dor", não se mostrando indiferente a experiência, mas aproveitando cada momento, como sendo privilégio para permitir falar, criar, transformar e mudar a si mesmo e propondo novas ideias na intervenção enquanto ser-no-mundo.

\section{Organização do Estágio Docente: o cuidado do início ao fim}

Este artigo, fruto de uma abordagem qualitativa, é um estudo descritivo, do tipo relato de experiência, realizado por uma mestranda, sob a supervisão do professor da disciplina optativa Interfaces Saúde e Educação, do curso de graduação em Psicologia de uma universidade pública do Vale do São Francisco, no período de junho a novembro de 2017. A disciplina está presente na grade curricular do curso de Psicologia, mas aberta a outros cursos como eletiva. A carga horária referente a disciplina foi de 60 horas, com quatro horas semanais, subdivididas em dois dias da semana, no turno matutino.

O Programa de Pós-Graduação em Formação de Professores e Práticas Interdisciplinares (PPGFPPI) trabalha a formação docente através da discussão, estudos e orientação em pesquisas preocupadas em seus vários aspectos com a educação. Um dos componentes para aprovação nas etapas avaliativas do programa se dá por intermédio da comprovação de exercício docente no ensino superior ou realização de estágio em alguma disciplina e espaço de interesse do aluno, sendo supervisionado pelo docente e posteriormente apresentando relatório com avaliação da atividade. Para este relato de experiência utilizou-se como registros as informações contidas no diário de bordo e o relatório de estágio docência apresentado ao PPGFPPI, como requisito avaliativo.

A ementa da disciplina apresenta como objetivo analisar a inter-relação entre Saúde e Educação, ampliando a compreensão do papel do psicólogo e do profissional de saúde na interface destas áreas. Matricularam-se na disciplina 15 alunos, sendo 13 desses do curso de Psicologia e estando entre o $6^{\circ}$ ao $9^{\circ}$ período. Uma aluna do curso de Ciências Sociais da mesma instituição e outra que se matriculou, mas não esteve presente, foram únicas matriculadas na condição de disciplina eletiva. As aulas foram realizadas em sala de aula, além de práticas vivenciadas em uma sala preparada para atividades grupais.

Ao todo foram vivenciadas 26 aulas, sendo a disciplina organizada em dois grandes blocos temáticos. O primeiro referente sobre o cuidar na Educação e Saúde em suas diversas perspectivas, discutindo aspectos teóricos de autores como Heidegger (2005), Boff (2013; 2014), Freire (2015) e Morin (2000). O segundo bloco se referiu a tópicos de interesse da Educação e da Saúde, refletindo sobre temáticas diversas como: medicalização na educação, reflexões sobre fracasso escolar e dificuldade de 
aprendizagem, educação integral e contextualizada, violências no contexto escolar - drogas, automutilação, suicídio, preconceito, bullying, indisciplina, gênero, sexualidade e direitos humanos, infâncias, ludicidade e saúde mental, Relação entre escola e família e Subjetividade e aprendizagem cognição, afetividade e corporeidade, Saúde do profissional de educação e humanização nos programas de saúde e educação.

Antes de iniciar as aulas da disciplina, foram realizados dois encontros para planejamento e levantamento de bibliografias que facilitassem a discussão sobre as temáticas preparadas. Além de realização de contatos com profissionais parceiros que pudessem contribuir acerca dos tópicos de interesse da educação e da saúde.

As aulas foram facilitadas no primeiro momento pelo docente e mestranda e no segundo momento obteve a contribuição de profissionais e pesquisadores convidados que mediaram as discussões relacionadas aos tópicos de interesse em Saúde e Educação. Em cada aula eram realizadas práticas diversificadas: técnicas grupais, exposição de documentários, relatos de pesquisas e experiência, discussões e práticas corporais.

Foram realizadas duas avaliações da disciplina, sendo executada a partir de textos acerca de temáticas que mais interessaram o aluno e produções escolhidas por cada um apresentando o sentido da disciplina para suas reflexões enquanto profissional em formação. Disponibilizaram-se materiais para a leitura prévia dos assuntos para os discentes, favorecendo maior participação nas discussões em sala de aula.

Para tanto, iremos relatar a experiência vivenciada nas 10 primeiras aulas, referente ao bloco sobre Cuidar, no intuito de indicar a experiência vivenciada no estágio docência como processo formativo no ensino superior pelo ethos do cuidado.

\section{O ethos do cuidado na prática do estágio docente no ensino superior}

O estágio docência foi todo permeado de reflexão crítica, onde a teoria e a prática estiverem lado a lado, nenhuma se sobrepondo a outra, estando numa mediação harmoniosa e explorando saberes necessários ao melhor modo de estar no mundo. Como afirma Bondía (2017), a experiência está cada vez mais rara, justamente por não darmos o tempo necessário para permitir que haja uma conexão significativa entre a reflexão e a prática. Assim, a intenção ao longo da vivência desta disciplina foi também cuidar do jeito de pensar, tornar cada momento uma oportunidade para o desenvolvimento de educadores, sobretudo na dimensão pessoal com os respectivos desdobramentos profissionais.

No primeiro dia de aula tivemos como atividade a dinâmica “coração partido" para apresentação e reflexão de si mesmo. Para essa dinâmica, foi entregue um papel em formato de coração cortado em duas partes, de modo que cada um era convidado a escrever uma qualidade positiva e negativa de si. Em seguida, os participantes se apresentaram e fizeram suas observações. Foi visto que estamos cotidianamente fazendo escolhas, entre uma coisa e outra. Assim como também optando em ser algo ou 
não ser. Segundo Heidegger (2005) todo nosso descortinar enquanto presença de cuidado no mundo se faz pela atitude e disposição de abertura. Os estudantes se mostraram disponíveis, mesmo que a relação de confiança ainda de início não tenha sido estabelecida.

Após as apresentações foi solicitado que todos colocassem os pedaços escritos, de modo a observar quais outras qualidades se identificavam. A partir disso foi compreendido que somos também um pouco do outro e o outro vai constituindo a nossa particularidade. Boff (2014), ao falar do cuidado com o outro, mostra que estamos envolvidos em um emaranhado de relações que nos provoca, evoca e convoca a sermos quem somos.

A formação pelo ethos do cuidado parte das reflexões, passando da dimensão do pessoal a constituição de novos modos de pensar. Tanto Heidegger (2005) quanto Freire (2015) mostram que nunca nos realizamos totalmente, estamos sempre em buscas, somos caminhantes. Assim, o docente da disciplina estimulou a reflexão através do questionamento: como eu dialogo com as minhas polaridades? Com essa pergunta, pensando no processo de estágio docência, em que o professor se forma na prática, anuncia-se o desafio de ser um "aventureiro", pois mesmo planejando e vivenciando em outros ambientes, a experiência é única, de modo que vivemos o inacabamento com o outro e que é isso que a dá consciência em relação a prática pedagógica (FREIRE, 2015; BONDÍA, 2017).

Após essas reflexões foi apresentado o programa da disciplina, os processos avaliativos e proposto os acordos necessários para o andamento ao longo do semestre. Ao ser experimentado o ethos do cuidado de maneira efetiva na prática do estágio docência foi fundamental que vivenciássemos o que traz Freire (2015) ao dizer que ensinar exige estética e ética, no que tange a intervir nos modos de pensar dos estudantes e junto a eles mudar o nosso olhar e escutar suas indicações para que a docência seja realmente formativa.

$\mathrm{Na}$ segunda aula, o tema norteador foi o cuidado, em que buscou-se facilitar a reflexão a partir das perspectivas de Heidegger (2005) e Boff (2013; 2014). Trazendo, pois, a importância de que o cuidado para Heidegger vem permeado da compreensão de ontologia do ser humano, ou seja, faz parte do homem, o homem é cuidado. Boff $(2013$; 2014) trata acerca da ética do cuidado, como sendo um revisitar a existência, tendo consciência de que estamos ligados uns aos outros e a terra onde estamos.

Importante trazer a reflexão desses pensadores do cuidado, refletindo que se não cuidarmos vamos adoecer e morrer, assim também como os recursos a nossa disposição, resgatando o sentimento de pertença, respeitando, vivendo e pensando de maneira sustentável, sem explorar e nos responsabilizando para as gerações que estão e que vem posteriormente. Para Bondía (2017), a experiência para ser sentida pelo outro, necessita ser transpassada de paixão, trazendo inclusive as incertezas. No fazer docente, o estudante passa a creditar confiança quando se trata de assuntos que carregam esse saber afetivo, que não somente se grava a nível intelectual, mas se sente e se vive.

$\mathrm{Na}$ terceira aula, discutiu-se acerca do pensamento de Edgar Morin (2000) e o pensamento complexo, como ideia de cuidado numa perspectiva planetária. Iniciou-se a aula dispondo duas cadeiras. 
Livremente em uma das cadeiras, um aluno poderia sentar e após quem desejasse poderia ocupar a outra disponível. Ao sentar em uma das cadeiras era sinalizado um tempo de um minuto, para que ambos não dissessem nenhuma palavra e apenas se olhasse. Após este tempo, ambos os alunos, caso desejassem, poderiam se expressar de maneira respeitosa e cuidadosa. Esse foi um momento intenso, em que vieram à tona emoções e palavras que emanaram verdadeiro cuidado a si e ao outro. $O$ intuito foi trazer que não estamos sozinhos em meio ao planeta em que vivemos e que o outro muito colabora para minha constituição.

O cuidado, conforme Boff (2013), nos revela que não somos seres totalmente independentes, precisamos do outro para nos apoiar. Os gestos, palavras, pensamentos e sentimentos no espaço de uma formação cotidiana de cuidado ajudam aos estudantes e educadores a percorrer caminhos de fortalecimento nas crises existenciais, seja dentro ou fora da vida acadêmica.

Nesta aula foi importante ter discutido as ideias de Morin (2000) na formação, pois parte da ideia de que o ecossistema que nos rodeia, produz saberes, acumula experiências, vive desilusões e afetos e não mantemos a atenção para os sinais demonstrados sejam entre as pessoas ou planetário. Morin (2000), em seus escritos, se mostra descontente com o paradigma colocado pelo Ocidente, que degenera e compartimentaliza os saberes de maneira a mutilar e fragmentar o conhecimento. Sobre isso, os alunos participaram ativamente da discussão de modo a pensar sobre as questões de religação das culturas da humanidade e cultura cientifica e não separá-las, refletiu-se sobre o compromisso com o presente e o futuro e o aprofundamento da transdisciplinaridade.

O ethos do cuidado na prática de pensar sobre a interligação de conhecimento entra em conformidade com a perspectiva "freireana" ao assumir que a experiência política, histórica, cultural e social das pessoas nunca podem ser um obstáculo na prática docente, mas sim uma oportunidade para unificar e articular o saber, aprendendo com o outro e com a realidade (FREIRE, 2015). É importante que o docente em sua formação esteja revestido de abertura para compreender e escutar mais o que os estudantes trazem do seu cotidiano e, particularmente, de seus mundos.

Na quarta aula a temática que foi sobre o pensamento de Paulo Freire na formação de educadores. Iniciou-se a aula solicitando para a formação de grupos, em que conversariam sobre os aspectos de diálogo que os envolviam, a partir das seguintes questões: Como percebem suas relações dialógicas? Consegue tirar tempo para dialogar com as pessoas? Como avaliam esses processos? Depois teriam que formular uma frase que completasse: "Diálogo é...” De modo geral, os grupos expuseram que "é contato entre pessoas e contato com o mundo e o outro".

Foi discutida a história de Paulo Freire e seu envolvimento com o aspecto da educação dialógica. A experiência de compartilhamento através do diálogo em sala de aula leva-nos a reflexão sobre o cotidiano e de como damos significado às experiências. Para tanto, utilizou-se de palavras norteadoras para mediar a discussão: diálogo, curiosidade, inacabamento, compartilhamento, emancipação, leitura de mundo, problematização, ação-reflexão, autonomia, aprendizado conjunto, conscientização, escuta e 
criticidade. Em cada palavra era desenvolvida breve discussão sobre as ideias "freireanas", realizando aporte com outros teóricos e com as experiências seja na comunidade ou na convivência junto aos colegas universitários. Por fim, foram distribuídos alguns trechos do livro Pedagogia da Autonomia de Paulo Freire. Sendo um convite para que cada aluno pudesse ler e trazer à tona as suas compreensões mediante o trecho lido. Ao avaliar com os alunos, eles ficaram bem curiosos para falar mais de Freire e ficou combinado de dar continuidade.

Alguns dos estudantes não conheciam quase nada sobre Paulo Freire, sendo uma boa oportunidade para se aproximar de um teórico que contribui para as várias áreas de saber, seja na educação ou na saúde. Como afirma o próprio Freire (2015), um pequeno gesto pode representar muito na vida de um aluno. A experiência docente é mesmo viver o inesperado, pois estando no mesmo estado do país em que Paulo Freire nasceu, muitas pessoas ainda não conhecem sua obra e muito menos seu pensamento que provoca transformação com métodos simples e possíveis de serem vividos em diversos contextos.

Além de Paulo Freire, a discussão foi envolvida sobre Educação Popular em Saúde. Para fundamentar foi apresentado o vídeo sobre a história de Paulo Freire e sua experiência inicial com o método de alfabetização de adultos. $\mathrm{Na}$ área da saúde muito tem se discutido sobre o pensamento de Freire e a educação popular pensada como promoção de saúde e empoderamento da população.

$\mathrm{Na}$ discussão entrou-se num consenso de que nossa construção quanto à saúde é envolvida de ações paternalistas e com a educação popular a ideia é que o sujeito compreenda e busque junto a comunidade estratégias educativas que fortaleçam a sua qualidade de vida e das pessoas que estão ao seu redor. Assim, as ações de educação para a saúde envolvem o sentido de vida, uma verdadeira solidariedade comunitária.

No segundo dia dessa discussão foi apresentado o vídeo sobre a Caravana da $\mathrm{Arte}^{2}$, uma experiência de educação popular em saúde em Fortaleza-CE e que agrega arte, formação, informação, educação e saúde através de cantos, poesias e envolvimento da população (DANTAS; DANTAS, 2014). Os alunos viram como uma novidade para a vivência em suas futuras práticas e que tem condições de serem vivenciadas, respeitando o território em que estiverem presentes.

Conforme Boff (2014), a criatividade tem como base à liberdade que respeita e pensa também no outro. Só um ser livre poderá melhor contribuir onde estiver, na doação de tempo e disponibilidade ao outro, assim como a si mesmo. Freire (2015) mostra que ninguém se liberta sozinho, nos libertamos conjuntamente. A proposta de trazer à educação popular para a prática no estágio docente se mostrou como elemento potencial de que tudo é possível levar o nosso modo de pensar, utilizando-se da arte e das diversas linguagens estéticas em educação e saúde.

${ }^{2} \mathrm{O}$ vídeo poderá ser acessado através do link: https://www.youtube.com/watch?v $=\mathrm{CK} 2 \_$SaTy4Q 
Vivenciou-se ainda como oficina os aspectos de saúde que envolviam a realidade de cada aluno. Para tanto, solicitou-se que desenhassem a palma da mão num papel sulfite e que no dedo polegar pudessem escrever: como estou? No dedo indicador: quais as práticas populares em saúde são vividas na minha família? Dedo médio: como vejo os aspectos de saúde na minha cidade? No dedo anelar: qual sugestão tenho para enfrentamento das dificuldades quanto a saúde na minha cidade? No dedo mindinho: uma palavra de motivação para nós e aqueles que promovem e discutem sobre saúde. Depois desta atividade os alunos discutiram suas respostas em duplas. Após, relacionou-se com a Política nacional de educação popular em saúde com as vivências e possibilidades de ações para promoção de saúde (BRASIL, 2013) fortalecendo o compromisso com a universalidade, a equidade, a integralidade e a efetiva participação popular no SUS, além de propostas que possibilitem que saúde aconteça, a partir do respeito aos saberes populares, ancestralidade, ao diálogo e a inserção do SUS as comunidades tradicionais no cuidado em saúde de maneira intersetorial e discussões multiculturais.

Compreendendo que o ethos do cuidado na formação docente se rege pelo olhar político, o educador não pode se mostrar neutro, sobretudo as demandas sociais suscitadas pelo grupo de alunos. Não se pode deixar as angústias pessoais e sociais do lado de fora da sala de aula. É ali que se vê como espaço de luta e de tomada de consciência. Como mesmo diz Freire (2015), o verdadeiro educador gosta de ser gente e não pode se eximir da presença do mundo.

$\mathrm{Na}$ sexta aula foi passado o documentário "Quando sinto que já sei”" (LIMA; LOVATO; PEREZ, 2014). Esse documentário trata das preocupações com as práticas vividas no processo escolar. principalmente práticas que levam a pensar numa escola prazerosa de estar. Para bem educar precisa-se de abertura e tempo. A escola, nesse sentido, pode pensar ainda mais a vivência de cidadania ligada a totalidade, sendo a aprendizagem um desdobramento do modo significativo de aprender, de maneira afetivo e contextualizada.

Para muitos alunos ficou a mensagem de que precisamos repensar nossas práticas, permitir que a "liberdade de aprender" aconteça. Rogers (1971) em sua obra acerca da educação, trouxe que a aprendizagem se dá quando o aluno compreende qual significação o conhecimento tem para ele, originando assim aprendizagens com autoconfiança e utilizando de criatividade para expressar o que aprender. Cada aluno extraiu um sentido por meio do documentário, vivenciou-se uma interpretação pela sua presença de cuidado, seja no momento atual como em seu processo de devir (HEIDEGGER, 2005).

$\mathrm{Na}$ oitava aula discutiu-se acerca da Metodologia Viva, um conceito que está em aprofundamento por Ribeiro (2016). O autor evidencia que a relação é o viés da Metodologia Viva, de maneira a perceber que através do diálogo o ser se transforma e se afeta por outro, resignificando suas ações. A aprendizagem significativa está para além do conteúdo, é parte do interesse do aluno, ligando-o a realidade. A questão do afeto deve ser mais aprofundado por nós em nossas formações. O afeto que propague motivação,

${ }^{3} \mathrm{O}$ vídeo está disponível no link: https://www.youtube.com/watch?v=HX6P6P3x1Qg 
curiosidade e melhor ação no estar consigo e com o outro. A relação é o meio propício para que se alcance melhor conhecimento, já que haverá um despertar para aprofundar mais sobre sua própria aprendizagem. Para tanto, compreende-se que a curiosidade se dá pelo contágio para com os outros, nas relações.

Ampliando a visão de afetividade, pode-se pensar que esta é algo que tem que envolver todas as nossas ações, estando atento ao que ocorre ao nosso redor. Dessa forma, precisamos entender que as relações devem se implicar de cuidado, na disciplina, na autoridade, no rigor e na exigência por qualidade de maneira equilibrada. Muitas perguntas ficaram como processo de síntese dessa aula: Quando não há prazer nos processos educativos o que devo fazer e como continuar? O que me prende ainda na vida? Qual o sentido para mim de aprender?

$\mathrm{Na}$ nona aula foi realizado o processo de avaliação, em que cada aluno trouxe escrito sobre alguma temática que o envolveu e uma pessoa faria a junção dos textos produzidos. Foi interessante este momento porque possibilitou a expressão da subjetividade, de modo que cada um pode expor suas descobertas, suas angústias e expectativas para mudança no futuro. Nos escritos e nas falas os alunos se mostravam, se revelavam e se envolviam nas falas uns dos outros.

O intuito da avaliação partiu da premissa de que o discurso se mostra como articulação da disposição de ser-no-mundo, como nos diz Heidegger (2005). Assim, em cada texto lido, o aluno se revelava, se desnudava e mostrava ao grupo o seu modo de pensar, além de expressar as transformações reflexivas vivenciadas ao longo dessas aulas articuladas numa formação pelo ethos do cuidado.

Assim como os alunos, os docentes foram também escrevendo e produzindo reflexões, compartilhado pelo diálogo. Conforme Freire (2015), o diálogo inquieta pois causa no outro afetações e curiosidades. Muitos alunos, nesse caso, mostraram-se interessados em buscar conhecer mais alguns dos teóricos estudados, colocando em suas práticas futuras saberes discutidos nas aulas.

Houve interação dialógica entre todos, acrescentando o modo de pensar numa visão de sensibilidade para com a escuta de um outro que também faz refletir sobre mim. Uma avaliação como essa se torna bastante oportuna, sobretudo em situações onde emaranhados de conteúdos são despejados para serem decorados. Para concluir, trabalhamos a fábula "Os Humanus cuidando da Humanidade”, em que os participantes recebiam cartões com cores diferentes e a partir do momento em que se falava sobre a cor referente, o participante cuidaria dos outros de diferentes formas. Todos participaram de maneira alegre, levando a aproximação do grupo com maneiras simples de cuidar do outro, seja com um aperto de mão, como também com um abraço. Por fim, foi feito o sorteio do Amigo Cuidador, tendo como proposta, que ao longo das aulas, fosse disposta um saco em que pudessem enviar bilhetes ou outras coisas que desejassem, como modo de cuidar do outro.

O exercício que foi pensado a ser vivenciado de maneira prática, condiz com o pensamento de Boff (2014) quando trata que o cuidado é uma forma de viver, de se expressar. Este seria então o momento de exercitar e perceber como o grupo também mostra seu modo de cuidar. Na formação, o 
cuidado tem a dimensão da reciprocidade, do dar e receber e entender que a todo o momento podemos cuidar e ser cuidados.

\section{Avaliando o processo de estágio no ensino superior}

A realização deste estágio docente no ensino superior regido pelo ethos do cuidado foi possível pela confiança entre o docente e a estagiária. O estágio como preparação de formação é, pois, uma maneira de compreender que a construção se dá conjuntamente, numa relação horizontal, aberta e autêntica. Ao longo do processo, compreendeu-se que o professor em qualquer instância que estiver deve aprender a conviver para bem viver com aqueles que estão junto ao seu trabalho docente. Que o professor precisa estar num processo de interação relacional, para entender o que favorece a aprendizagem de maneira tranquila e prazerosa.

Freire (2015) afirma que a educação é uma intervenção no mundo. Ao trazer para a prática vivenciada, estivemos em muitos mundos, ou seja, na vida de cada aluno participante da disciplina, mostrando que é possível viver a transformação que sonhamos, começando por nós mesmos e sempre respeitando os tempos e os espaços onde estivermos. O cuidado se dá na formação de maneira respeitosa, contínua e fraterna, preocupado com o seu bem-estar e consequentemente com o outro, vivendo juntos a experiência de se educar, cuidando.

No início, por conta da pouca experiência na docência universitária, houve momentos de tensões e medos de não dar conta. Mas que com a ajuda e orientação do professor regente e da turma o sentimento foi de acolhida diante das propostas e discussões lançadas. Na primeira aula, ainda não sabendo muito o que se podia ou não fazer na prática docente, vivenciou-se um teste para compreender que somente a discussão não daria conta de tudo o que o grupo desejava. Assim, em conversas avaliativas e acompanhamento, pensou-se em maneiras diversificadas de trazer uma educação apaixonada e apaixonante que envolvesse a relação de cuidado.

Por meio das técnicas grupais, a prática docente centrada no ethos do cuidado foi provocativa, na dimensão de que a experiência expõe o sujeito, de que sempre acontece algo que afeta e que atravessa perigosamente para a transformação (BONDÍA, 2017). Não se pode dizer que a experiência na prática docente com e pelo cuidado não interpelou por uma mudança, pelo contrário o saber fora significativo e o que antes era estranho, se tornou conhecido, mostrando que é preciso fazer mais para que outros experimentem deste fazer carregado de atenção e zelo para com a sua vida e a do outro.

Do início ao fim do processo de estágio, o professor regente acompanhou todas as ações e possibilitou muito espaço para que se experimentasse a prática docente no ensino superior, como lugar de encontro. Porque aula também é encontro, não somente de saber, mas de viver. Foi positivo o apoio e a certeza de não estar só, diante da primeira experiência no exercício docente em uma universidade. Além de que o desejo era de que os alunos vissem a disciplina como lugar prazeroso e cuidadoso ao longo 
de todo o semestre. Assim aconteceu, talvez até mais do que se imaginava. O cuidado após refletido, foi levado com zelo na vida de cada aluno.

Freire (2015) indica que o aprendiz de professor, precisa pensar uma prática regida pela reflexão crítica. Pensar criticamente uma prática para melhorar a outra. Ao longo de todo o processo do estágio docência no ensino superior o ethos do cuidado aconteceu pela constante avaliação, planejamento e comunicação entre o professor e a estagiária. Isso fez com que fossem aprimorados práticas e pensamentos quanto ao processo vivencial e reflexivo de cuidado junto aos alunos da disciplina de Interfaces Saúde e Educação.

$\mathrm{Na}$ sala de aula se refletiu e foi possibilitada abertura com suas diversidades, foram quebra de tabus, no refazer e fazer docente, vivendo a alegria dos bons resultados e observando que todos foram crescendo no processo de formação potencializadora de si para com o outro. Numa ação de preocupação e ocupação para com os ambientes que podem ser lugares cuidadores nas suas relações.

Outro ponto que favoreceu muito para o desenvolvimento docente pelo ethos do cuidado, foi o planejamento construindo conjuntamente, de maneira a condição de enquanto estagiária se sentir envolvida e implicada no processo. Houve a clareza da organização e dos objetivos que gostaria de atingir num processo de formar a ação, para melhor qualidade no hoje e no futuro de experiências exitosas no meio profissional.

Estar no exercício docente num lugar desconhecido, na universidade, foi uma verdadeira aventura, que necessita de coragem já que não se sabe aonde vai chegar. Nesta experiência a sensação que dá é que a ação envolvida de serenidade e liberdade nas produções, leva para além do que se conhecia da prática até então. Percebe-se que na prática o educador vai se constituindo, sendo a docência um verdadeiro ofício de artesão, de construção e reconstrução de práticas de cuidado que integram a vida, que sejam significativas e que permitam revelar as subjetividades de maneira generosa e feliz, dedicando o seu ser de modo surpreendente a confirmação da beleza de educar.

\section{Considerações - o fim para novos começos}

O estágio docência enquanto experiência do ensinar no processo de formação, ao se dar pelo ethos do cuidado, se mostrou momento para refletir, criar e discutir propostas significativas para um exercício profissional que impacte em transformações e propiciem motivação tanto para o professor quanto aos alunos. Para uma prática regida pelo ethos do cuidado, precisa mais do que fazer, de saber, precisa de vontade. Pois, o professor está constantemente se construindo e reconstruindo, para isso é necessário haver abertura, disposição, escuta e desejo de transformar muitas vidas, seja a sua ou a de outros pela educação.

O cuidado foi possível de ser vivenciado na prática do estágio docência por vários aspectos, diálogo e planejamento constante entre professor regente e estagiária, abertura do grupo de alunos para 
vivenciar as práticas de cuidado, atenção e escuta para com as demandas trazidas pelos alunos e avaliações cotidianas do fazer docente. Uma realidade de ethos do cuidado exige esforço, estudo e vontade de propagar e desenvolver bons momentos em sala de aula, para que se lance no mundo e se multiplique através dos alunos. Assim, o estágio docente no ensino superior não se dá de maneira isolada e individual, mas sim coletiva, buscando ética e estética para aprimorar, propiciando aulas atrativas, reflexivas e cuidadosas.

Portanto, a prática envolvida do ethos do cuidado se mostra como uma experiência exitosa e oportunidade única de exercitar a docência na universidade com orientação, leveza, sensibilidade e atenção para com os caminhos percorridos. O desejo de contribuir e inovar no cotidiano das ações educativas se eleva, numa esperança de qualificar ainda mais os espaços numa educação que envolve cuidado e implicação. Com isso, o cuidado é um constante meio de chegar a novos começos, pois a formação significativa marca histórias e sinaliza para novos modos de olhar para si, para o outro e o mundo.

\section{Referências}

ANTONI, Marcella Ranheri de; CALDAS, Thuanny Carolina Gerhardt; DE ANTONI, Clarissa. Fatores de adoecimento dos estudantes da área da saúde: uma revisão sistemática. Revista Psicologia Saúde e Debate, v. 3, n. 1, p. $99-126,2017$.

BONDÍA, Jorge Larossa. Tremores: escritos sobre a experiência. Belo Horizonte: Autêntica Editora, 2017.

BOFF, Leonardo. O cuidado necessário: na vida, na saúde, na educação, na ecologia, na ética e na espiritualidade. Petrópolis: Vozes, 2013.

BOFF, Leonardo. Saber cuidar: ética do humano compaixão pela terra. 20 ed. Petrópolis, RJ: Vozes, 2014.

BRASIL. Ministério da Educação. Lei de Diretrizes e Bases da Educação Nacional. Lei n. 9.394/96. Disponível em: http://www.planalto.gov.br/ccivil_03/Leis/L9394.htm. Acesso em: 10 mai. 2017.

BRASIL. Ministério da Saúde. Política Nacional de Educação Popular em Saúde no âmbito do Sistema Único de Saúde (PNEPS-SUS). Portaria no 2.761, de 19 de novembro de 2013. Disponível em:< http://bvsms.saude.gov.br/bvs/saudelegis/gm/2013/prt2761_19_11_2013.html>. Acesso: 10 mai. 2017.

DANTAS, Uirá; DANTAS, Vera. Nas Asas da Arte. 2014. (26m). Disponível em:< https: / /www.youtube.com/watch?v=CK2_SaTy4Q\&t=58s>. Acesso em: 10 ago. 2017.

FREIRE, Paulo. Pedagogia da autonomia: saberes necessários à prática educativa. 51 ed. São Paulo: Paz e Terra, 2015.

GOIS, Pamela Karina de Melo. Formação para a docência no ensino superior: realidade e desafios. EDUCERE - XII Congresso Nacional de Educação. 2017. Disponível em: < http://educere.bruc.com.br/arquivo/pdf2017/23418_11749.pdf>. Acesso 03 mai. 2019.

HEIDEGGER, Martin. Ser e tempo. Parte I. 15 ed. Petrópolis, Rio de Janeiro: Vozes, 2005. 
LIMA, Anderson; LOVATO, Antonio; PEREZ, Raul. Quando sinto que já sei. 2014. (78m). Disponível em:< https://www.youtube.com/watch?v=HX6P6P3x1Qg>. Acesso em: 10 ago. 2017.

MORIN, Edgar. Os sete saberes necessários à educação do futuro. 2ed. São Paulo: Cortez: Brasília-DF: UNESCO, 2000.

OLIVEIRA, Amanda da Silva Dias; PEREIRA, Maristela de Souza; LIMA, Luana Mundim. Trabalho, produtivismo e adoecimento dos docentes nas universidades públicas brasileiras. Psicologia Escolar e Educacional, São Paulo, v. 21, n. 3, p. 609-619, 2017.

RIBEIRO, Marcelo Silva de Souza. Metodologia Viva do professor da educação infantil: reflexões sobre o caminho do meio. Anais do XVIII Encontro Nacional de Didática e Prática de Ensino ENDIPE, Cuiabá, MT, pp. 944-955, 2016.

ROGERS, Carl R. Liberdade para aprender. Minas Gerais: Entrelivros, 1971. 